\title{
COLUMN STRENGTH REQUIREMENTS IN MULTI-STOREY SEISMIC FRAMES
}

\author{
E. L. Blaikie*
}

\begin{abstract}
This paper examines factors affecting the strength requirements of columns in multi-storey frames responding to seismic ground motions.

The examination is carried out using an inelastic static analysis approach and the concept of an "equivalent condensed frame". In particular, the influence of higher modes and the effect of varying the pattern of beam flexural strength over the frame height are evaluated.

It is suggested that the current capacity design approach of the NZ Concrete Design Code overstates the importance of higher mode effects while neglecting the potentially more important influence of the beam flexural strength pattern that is provided for a frame.

Some tentative modifications to the current column design procedure are suggested for future evaluation under inelastic dynamic response conditions.
\end{abstract}

\section{INTRODUCTION}

Inelastic dynamic analysis of multi-storey frames has established that relatively high column strengths are required if the ductility demand generated by seismic ground motions is to be spread throughout a frame $[2,4]$.

High ductility demand concentrated in a few structural members may exhaust their ductility capacity and is particularly undesirable in elements such as columns carrying high axial loads.

These observations have led to the suggestion, given in the commentary to NZS 3101, the NZ Reinforced Concrete Design Code [1], that columns should be designed to resist seismic loads using a capacity design approach that takes into account the effects of concurrency, higher modes and beam flexural overstrength on the column strength requirements.

This paper examines the possible affects of an additional factor that is not currently considered and suggests modifications to the current capacity design procedure for columns.

To enable the factors affecting column strength requirements in multi-storey ductile frames to be evaluated, the concept of an 'equivalent condensed frame' with its 'Load' and 'Resistance' lines is developed.

* Works corporation, Wellington.
However, as only a static inelastic analysis approach is used, the conclusions and suggestions arrived at can only be considered as tentative until they are evaluated under inelastic dynamic loading conditions.

The objective of the paper is to raise questions and, hopefully, to generate some discussion.

\section{EOUIVALENT CONDENSED FRAME}

Figure 1 (b) shows a beam plastic hinging collapse mechanism for a 10 storey frame. The lateral load required for the collapse mechanism to form is shown in Figure 1 (a). This is the familiar triangular distribution of seismic load, $F_{x}$, usually assumed in design, amplified by a factor $Q$.

To simplify the discussion that follows, a number of assumptions have been made. The seismic mass supported by the frame is assumed to be uniformly distributed over its height, and torsional and other three dimensional effects are ignored. However the principles that will be illustrated are quite general.

Figure 1 (c) shows an "equivalent condensed frame" model for the building with the same lateral strength and stiffness as all the bents in the frame being modelled. The column in the equivalent frame has the combined strength and stiffness of all the columns in the frame. The beam at each level has the combined stiffness of all the 


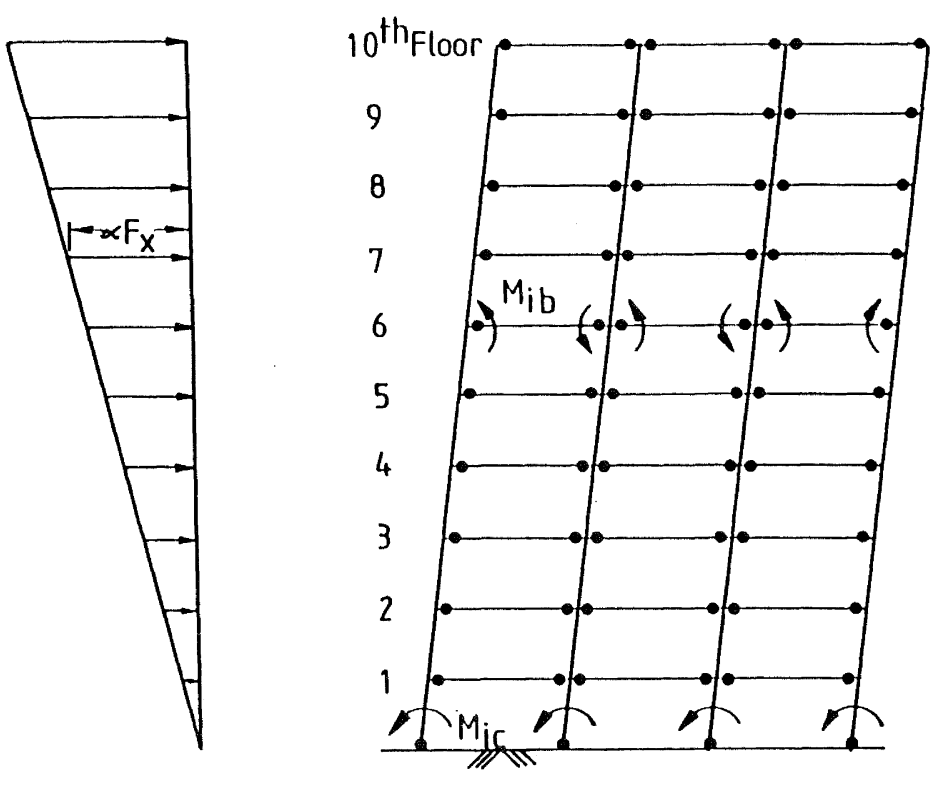

FIG 1 (A) SEISMIC LOAD $F$ (CODE DISTRIBUTION AMPEIFIED BY)
FIG 1(B) TYPICAL FRAME BENT BEAM PLASTIC HINGING COLLAPSE MECHANISM

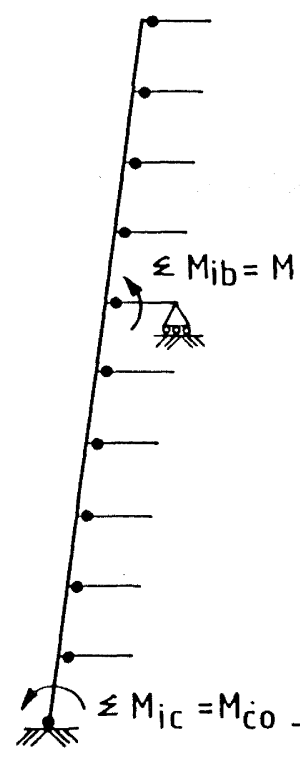

FIG 1 (C) EQUIVALENT CONDENSED FRAME

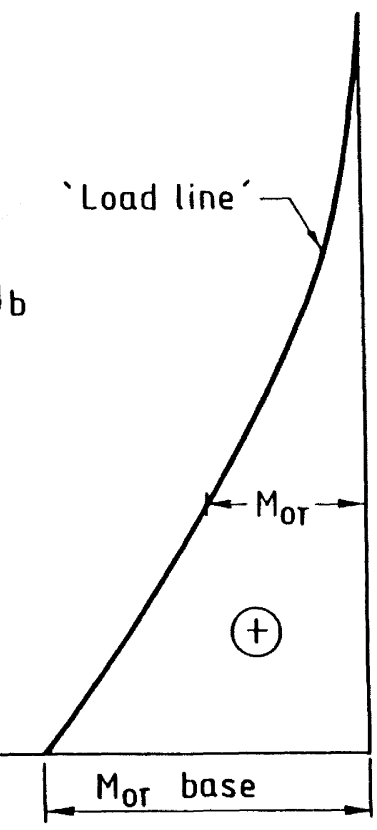

FIG 1 (D) TOTAL OVERTURNING MOMENT $\left(\mathrm{M}_{\mathrm{OT}}\right)$ - I LOAD LINE
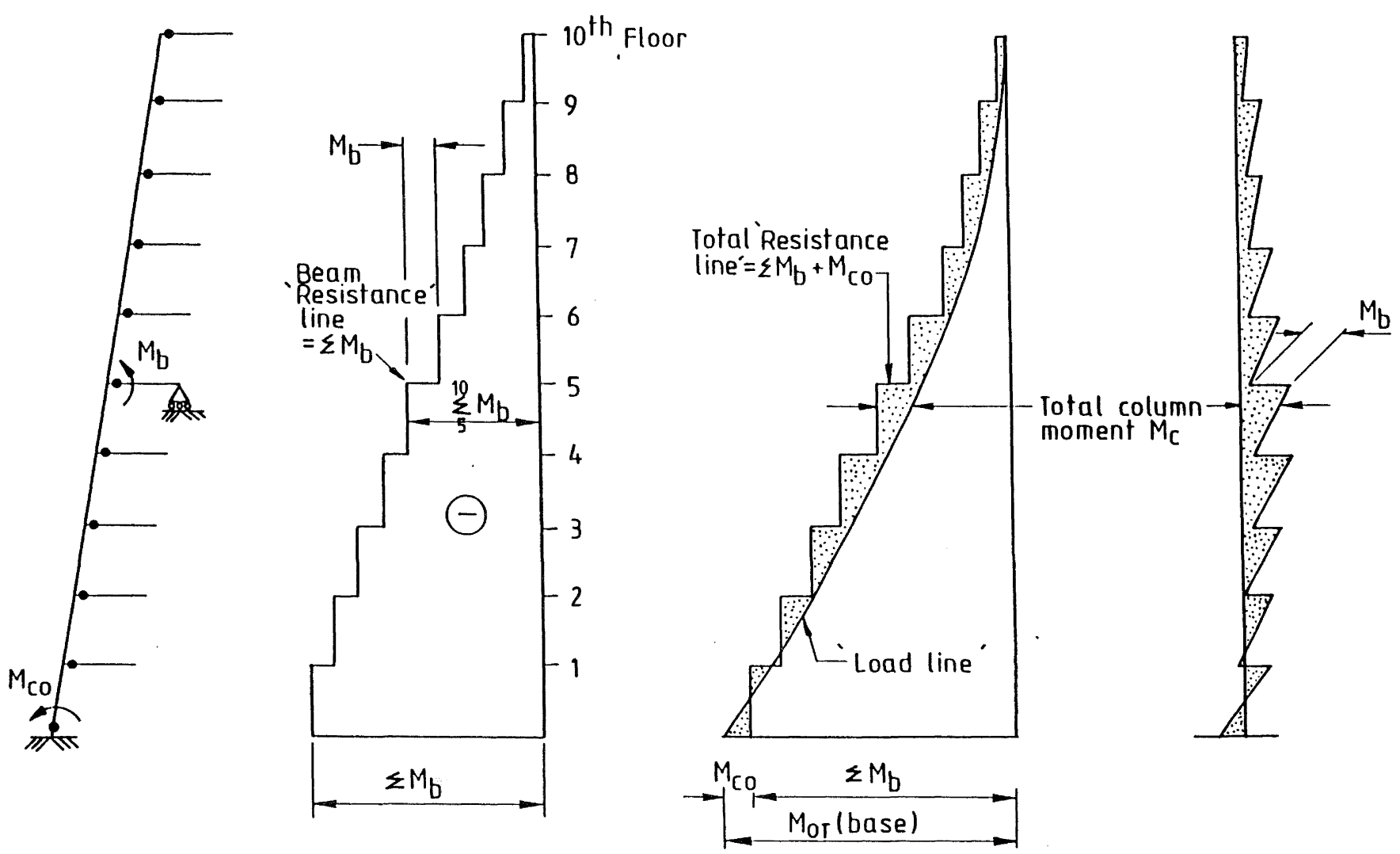

FIG 2 (A) EQUIVALENT CONDENSED FRAME FIG 2 (B) TOTAL OVERTURNING FIG 2 (C) TOTAL COLUMN RESISTANCE DUE TO BEAMS ONLY MOMENT

FIGURE 2 (D) TOTAL COLUMN MOMENT - PLOTTED RELATIVE 
half span beams in the frame at that level and its plastic hinge strength, $\mathbb{M}_{1}$ is equal to the combined flexural strength of all the positive and negative beam plastic hinges in the frame at the level being considered. To enable column centre line moments to be modelled, $\mathrm{M}_{\mathrm{p}}$ also includes the additional increment of moment generated by the beam shears acting at the column faces.

The axial load in the column of the equivalent frame is that generated by gravity loads only, as the seismic induced axial loads in the columns of the frame vectorially sum to zero.

\section{'Load Iine'}

The equivalent frame can be considered as resisting the lateral loads shown in Figure 1 (a) as a vertical cantilever. The resultant cantilever bending moments, corresponding to the formation of the collapse mechanism, are shown in Figure 1(d). These moments are the seismic overturning moments, M , for the building as a whole and in subsequent discussion they will be referred to as the "Load Line'. If $\mathrm{P}-\Delta$ effects, due to gravity loads were significant, they could also be included in $M$ and hence in the 'Load Line'. Otherwise column axial loads need not be considered further.

\section{'Resistance Iine'}

Figure 2(a) again shows the equivalent condensed frame. The overturning resistance at any level, due to the beams alone, can be obtained by summing the moments imposed on the column by all the equivalent beams above the level being considered. When all the beams are plastic hinging, as in Figure 2 (a), the beam "Resistance Line" is obtained as shown in Figure 2 (b). As indicated, the steps in this line at each floor level correspond to the beam plastic hinge strength, $\mathrm{M}_{b}$, of the adjacent beam.

When the collapse mechanism shown in Figure 2 (a) forms, equilibrium considerations dictate that the total overturning moment at the base of the equivalent frame, $M_{\text {oT }}$ (base) as shown in Figure $1(d)$, must equal the sum of the beam plastic hinge strengths, $\Sigma M_{1}$, plus $M$, the strength of the plastic hinge assumed to form at the base of the first storey column of the equivalent frame.

This equilibrium condition is shown diagrammatically at the bottom of Figure 2 (c). If $\left(\Sigma M_{b}+M_{c o}\right)$ is known for a frame, then $\mathrm{M}_{\mathrm{T}}$ (base) will be known and can be used toT evaluate, $Q$, the code load scaling factor required for the collapse mechanism to form (see Figure 1(a)). The collapse 'Load' line and total 'Resistance' line will then be fully defined for an assumed distribution of lateral load.

At any level over the height of the equivalent frame, the total column moment required for equilibrium is the difference between the overturning moment due to the applied load and the moment resisted by all the beams above that level. This means that the total column moment, $M$, is given by the difference between the 'Load' and 'Resistance' lines as shown in Figure 2 (c). The total column moment found by this method will be the sum of all the column moments at the corresponding level of the frame being modelled by the equivalent condensed frame.

The important point to note is that, at collapse, the column moment at any floor level is not primarily dependent on the strength of the adjacent beams at that level as it would be under elastic conditions. Instead, the column moment at any level is dependent on the distribution over the full height of the column of both the applied load and the beam moments that are being imposed on the column. This means that under inelastic conditions, the column moments can deviate from the value obtained from an elastic analysis even without considering the effects of overstrength, higher modes and other dynamic effects.

Figure 2(d) shows how the same total column moments shown in Figure 2 (c) can be plotted relative to a vertical axis which is the more familiar convention for plotting column moments. At any level, the slope of the 'Load Iine' in Figure 2 (c) and the moment plot in Figure $2(\mathrm{~d})$ must be the same as it indicates the inter-storey shear force.

With this in mind, it can be seen that the only difference between the two methods of plotting the moments is that the column moment in Figure 2 (a) is plotted relative to a stepped vertical line while in Figure 2 (d) it is plotted relative to a single vertical line. This observation should assist the reader with interpretation of the remaining figures.

\section{EFEECT OF HIGHER MODES ON COLUMN STRENGTH} REQUIREMENTS

The displacements of a building responding elastically to a seismic ground motion can be considered as a combination of modal displacements. During the response of such a building, the peak inertia loads at each floor level are proportional to the modal displacements (ie, for each mode, $m \ddot{x}=m \omega^{2} x$ where $\mathrm{m}=$ mass, $\ddot{\ddot{x}}=$ acceleration, $\omega=$ modal angular frequency, $\mathrm{x}=$ modal displacement). Therefore seismic loads can also be considered to be a combination of modal loads, $m \ddot{x}$.

As indicated by the above equation, the modal loads will have the same shaped distribution as the modal displacements providing the mass is uniformly distributed over the height of the building.

The inelastic dynamic response of a building during an earthquake is more complicated than this elastic behaviour, as restoring forces are no longer proportional to displacements and the deflected shape may be affected, for example, by concentrated column plastic hinging.

However, the effect of higher mode type loading can still be discerned in an inelastic dynamic response. Figure 3 

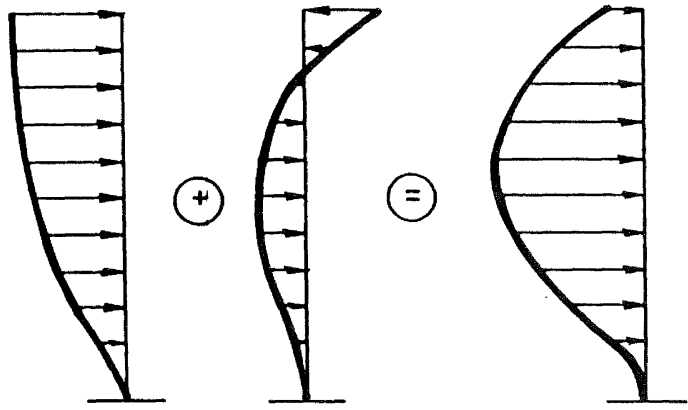

(a) st $^{\text {st }}$ mode (b) $2^{\text {nd }}$ mode

(c) $p^{s t}+2^{\text {nd }}$ mode
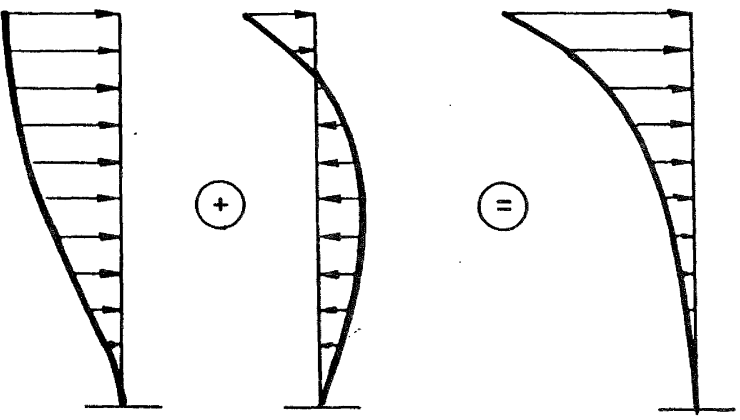

(d) $9^{\text {st }}$ mode $\left(\right.$ e) $2^{\text {nd }}$ mode

(f) qst $2^{\text {nd }}$ mode

FIGURE 3 MODAL LOAD COMBINATIONS

indicates how first and second modal loads can combine to give a dynamic load with the centroid of the applied load either higher or lower than that obtained from the triangular distribution of loading that is usually assumed in design. This redistribution of dynamic load due to higher modes tends to alter the 'Load Line' and column moments as indicated in Figure $4(a)$. As the column moments are the difference between the two resulting 'Load' lines and the 'Resistance' line they can be seen to be either amplified or reduced as a result of the second mode.

Previous studies, using inelastic dynamic analysis [2], indicate that beam plastic hinging tends to develop in waves that travel up and down the frame. These waves are generated by the higher mode imposed deformations and mean that, even at peak lateral response, all the beam plastic hinges may not form simultaneously. Therefore, the steps in the 'Resistance' line may not equal the full beam plastic hinge strength and consequently, higher modes may effect the shape of the 'Resistance' as well as the 'Load' line. The significance of this effect can only be evaluated using inelastic dynamic analysis which is beyond the scope of this paper. The 'Load' and 'Resistance' lines shown in Figure 4 (a) have been drawn to illustrate the principles involved. However it is still interesting to compare the resulting column moments with the flexural strength that would be provided for the column as a result of a design to NZS 3101 (Part 2).

The comparison will be made by considering the 4 th floor column moment which, for convenience, has been drawn as $2 \mathrm{M}_{\mathrm{p}}$, twice the 4 th floor beam plastic hinge strength, $M$. The corresponding beam and column moments for equilibrium of the 4 th floor joint of the equivalent frame under inelastic conditions are shown in the inset of Figure 4 (a).

Under elastic conditions approximately half the beam moment, $M_{b}$, would be carried by the columns above and below the joint resulting in a column moment of only $1 / 2 \mathrm{M}_{\text {. }}$. The current capacity design provisions of NZS 3101 would require these elastic column moments to be amplified for beam overstrength and higher mode effects. If the beam plastic hinge strength, $M_{1}$, is assumed to already include beam flexural overstrength, a design using the capacity design procedure in the commentary to NZS 3101 would then require a column strength of less than $M_{b}$ to be provided. This is only half the value of the maximum column moment, $2 \mathrm{M}$, in the example illustrated in Fig 4 (a). As the column moment is given by the deviation between the 'Load' and 'Resistance' lines this indicates that the current capacity design procedure assumes that only a relatively small deviation between 'Load' and 'Resistance' lines will take place. In fact, for the example

shown in Fig $4(\mathrm{a})$, the 'Load' line would have to lie within the extremities of the 'Resistance' line if column plastic hinging is to be avoided.

\section{EFFECT OF BEAM FLEXURAL STRENGTH PATTERNS ON COLUMN STRENGTH REQUIREMENTS}

Figure $4(\mathrm{~b})$ indicates how variations in beam plastic hinge strength over the height of the building can affect the shape of the 'Resistance Line' and therefore the column moments generated at collapse. Comparing Figures $4(\mathrm{a})$ and $4(\mathrm{~b})$ it can be seen that this beam plastic hinge strength pattern effect is similar to that generated by higher modes except that in this case, it is the 'Resistance' rather than 'Load' line that shifts.

The influence of the beam flexural strength pattern on column strength requirements is not considered in the current capacity design procedure [1]. This can be illustrated by considering the column moments corresponding to 'Resistance Line' (a) in Figure 4(b). 'Resistance Line'(a) has been constructed so that the deviation between the 'Load' and 'Resistance' lines at $3 \mathrm{rd}$ floor level results in a column moment of $2 \mathrm{M}$ that is twice the 3 rd floor beam plastic hinge strength $\mathrm{M}_{\text {. Th }}$. This large column moment is generated by the relatively large steps in the 'Resistance Line' at the first and second floor levels due to the assumption that strong beams were provided at these two levels. Therefore, the size of the 3rd floor column moment is not primarily due to the size of the beam strength provided at the $3 \mathrm{rd}$ floor level. 


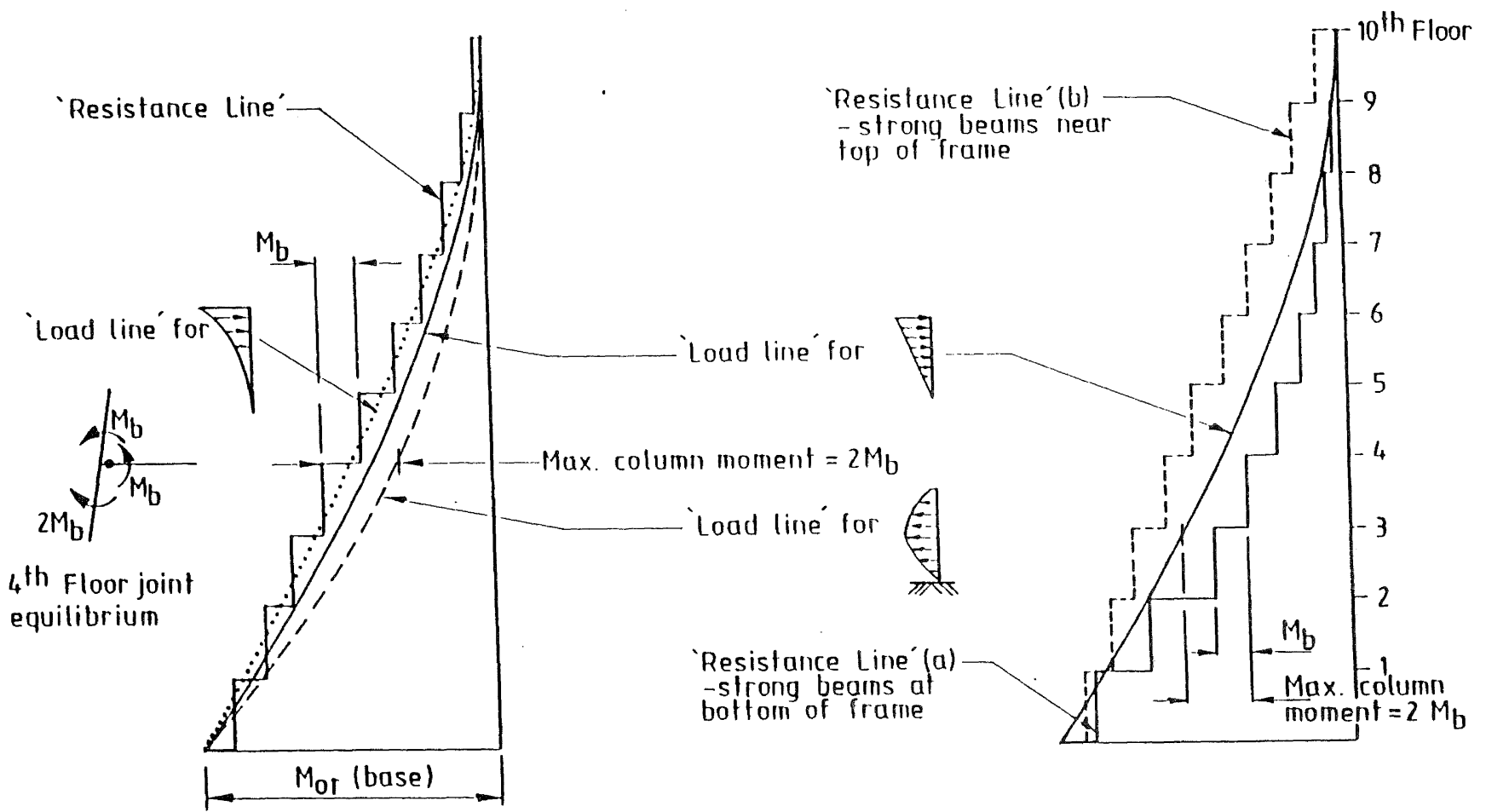

FIG 4 (A) EFFECT OF HIGHER MODES ON COLUMN STRENGTH REQUIRED FOR BEAM PLASTIC HINGING MECHANISM
FIGURE 4 (B) EFFECT OF BEAM STRENGTH PATTERN ON COLUMN STRENGTH REQUIRED FOR BEAM PLASTIC HINGING MECHANISM
Using the current capacity design procedure, the large beam strengths at lst and 2 nd floor levels would be reflected in the column strength provided at these two levels. However, they would not influence the column strength provided at the $3 \mathrm{rd}$ floor level where the column moment is affected just as much.

The effect that strong gravity dominated beams near the top of the frame have on the column moments is illustrated by 'Resistance Line' (b) in Figure 4(b). Once again the column moment at the level of each beam can be seen to be dependent on the overall pattern of beam flexural strength provided and not on the local beam flexural strength.

The beam flexural strength patterns and resultant shape of the 'Resistance' lines in Figure $4(\mathrm{~b})$ have been chosen to illustrate the principles involved. They are not intended to be typical and the column moments illustrated are again well in excess of those that would cause column plastic hinging in a frame as currently designed to NZS 3101 and its commentary.

An important difference between the higher mode effect illustrated in Figures $4(a)$ and the beam flexural strength pattern effect illustrated in Figure $4(b)$ is that an adverse beam flexural strength pattern may result in column plastic hinging under first as well as second mode type loading. Althougin higher modes generate significant forces they are associated with relatively small displacements. Therefore, if column hinges form, only small amounts of ductility should be required to "absorb" the higher mode displacements. However, if the beam flexural strength pattern and column strength provided results in a column plastic hinge forming under first mode type loading large column ductilities could be generated by the relatively large first mode displacements.

The relative magnitudes of first and second mode accelerations and displacements are illustrated in Table 1 for some examples of frames of varying height.

The ratios of displacement given in the table were derived from an elastic analysis. However, if it is assumed that the equal displacement principal holds true for both modes, the ratios will also give an indication of the relative size of the displacements generated by the two modes under inelastic dynamic conditions.

\section{EFFECTS OF COLUMN PLASTIC HINGE FORMATION NEAR FRAME MID-HEIGHT}

A column plastic hinge forming at the 6 th floor level of an equivalent frame affects the column moments in the remainder of the column as illustrated in Figure 5 .

When a column plastic hinge does not form at 6th floor level the 'Load Line' is as shown in Figure 5(a) with a corresponding total overturning moment at the base of the 
TABLE 1 : RELATIVE 1ST AND 2ND MODE ACCALERATIONS AND DISPLACEMENTS AT ROOF LEVEL

\begin{tabular}{|c|c|c|c|c|c|c|c|}
\hline \multirow{2}{*}{$\begin{array}{l}\text { Number } \\
\text { Storeys } \\
\text { in } \\
\text { Frame }\end{array}$} & \multicolumn{4}{|c|}{ Acceleration $(\% \mathrm{~g})$} & \multicolumn{3}{|c|}{ Displacements $(\mathrm{mm})$} \\
\hline & $\begin{array}{l}\text { Period } \\
\text { (sec) }\end{array}$ & 1st Mode & 2nd Mode & $\frac{\text { 1st Mode }}{\text { 2nd Mode }}$ & 1st Mode & 2nd Mode & $\frac{1 \text { st Mode }}{2 \text { nd Mode }}$ \\
\hline 6 & 1.4 & 0.592 & 0.322 & 1.8 & 288 & 15.8 & 18.2 \\
\hline 12 & 2.52 & 0.258 & 0.252 & 1.0 & 407 & 41.7 & 9.8 \\
\hline 18 & 2.99 & 0.226 & 0.250 & 0.91 & 502 & 64.6 & 7.8 \\
\hline 24 & 3.37 & 0.207 & 0.255 & 0.81 & 584 & 85.3 & 6.9 \\
\hline
\end{tabular}

\section{Notes :}

1. Sample frames taken from reference (5).

2. Modal analysis used the response spectrum given in DZ4203 for $\mu=R=Z=1.0$ and normal soils.

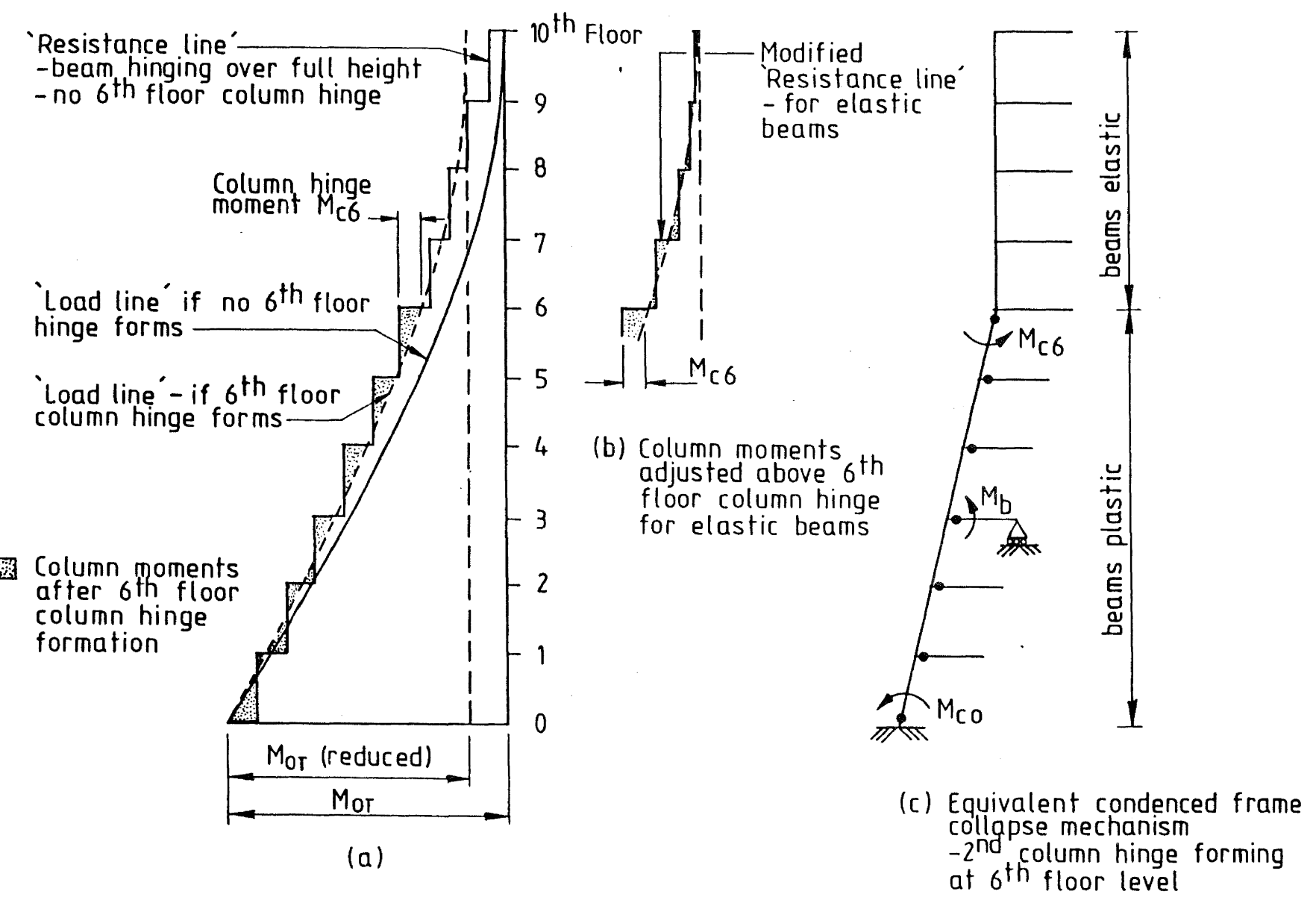


equivalent frame, $\mathrm{M}_{\mathrm{T}}$. However, if a column plastic hinge of strength $M$ forms at the 6 th floor level, the 'Load Elne' will then have to pass through a point on the 'Resistance Line' at the 6th floor level defined by the column plastic hinge strength. In this case the 'Load Line' required to form a collapse mechanism will be scaled down by a factor, $\mathrm{M}$ (reduced) $/ \mathrm{M}$ as indicated in Figure 5(T). Providing the column has adequate strength between the 1 st and 5 th floors, the beam plastic hinges over this height will still form as shown in Figure 5 (c) and the 'Resistance Line' below 6 th floor level will be unchanged. However above 6th floor level, beam plastic hinges are not required for the formation of the collapse mechanism shown in Figure $5(\mathrm{c})$. The steps in the 'Resistance Line' above 6th floor level will therefore generally correspond to elastic beam moments. As indicated in Figure $5(\mathrm{~b})$ the resulting modified 'Resistance Line' will then closely follow the new 'Load Line' as would be expected for an elastically responding portion of the frame.

The most important feature to note about Figure $5(\mathrm{a})$ is that a column plastic hinge forming at 6 th floor level reduces the column moments over the entire height of the frame. This suggests that a column plastic hinge could be intentionally detailed at, or just above, the frame midheight to limit column moments elsewhere. Such a design approach would be consistent with the general capacity design philosophy.

However, if the mid-height column plastic hinge formed during the dominant first mode response, it would tend to concentrate the ductility demand in the beams below the column plastic hinge level. Even so, permitting mid-height column plastic hinging does suggest a means of limiting column strength or ductility demand for peak load effects such as those due to higher modes or skew earthquake loading.

\section{MODIFIED COLUMN DESIGN PROCEDURE}

The investigation of factors influencing column strength requirements in multistorey frames outlined above suggests some modifications to the current capacity design procedure for columns.

At this stage the suggested modifications are based on static considerations alone. Therefore they can only be considered as tentative until they can be fully evaluated using inelastic time history analysis of frames for a range of seismic motions and beam flexural strength patterns. They are included at this stage primarily because they illustrate the potential implications of the investigation carried out so far. The following design steps modify the procedure suggested by Appendix $C$ of the commentary to NZS 3101 [1] for the capacity design of reinforced concrete columns. However the principles involved are also applicable to the design of columns in steel frames.
STEP 1. Carry out an elastic analysis to determine the required ideal beam strengths as at present.

STEP 2. Evaluate the flexural overstrengths of the beam plastic hinges, $M{ }^{\prime}$ ' and the column plastic hinge strength, for an Equivalent Condensed Frame similar to that shown in Figure 1 (c).

\section{Comments}

As in the current procedure, M should include all sources of over-strength as well as the additional moments due to the eccentricity of the beam shears at the

column faces relative to the column centre lines.

Also, as in the current procedure, the total ideal column plastic hinge strength to be provided at the base of the first story columns, M, should be 1.4 times the value determined from the elastic frame analysis for code loads (i.e. overstrength $\phi=1.4$ ). This will ensure that this critical part of the column has a strength that is comparable to that provided for the remainder of the column. Where some bents of the frame have significantly different beam flexural strengths because they resist high building torsion or other effects it may be necessary to analyse them as separate equivalent frames.

STEP 3. Using $M$ equal to the beam flexural overstrength, 作, and a column plastic hinge strength ${ }^{\circ}$ of $M$, construct a 'Resistance Line' similar co' that shown in Figure 2 (c) and a 'Load Line' corresponding to the formation of a collapse mechanism.

The basic total column moment, that will be factored later and used for the design of the columns, is then determined by taking the difference between the 'Load' and 'Resistance' lines as indicated in Figure 2 (C).

\section{Comments:}

In practice the column moments would be obtained by calculation instead of graphically. Also, allowing the column strength to reduce to the relatively small values that Figure 2(c) implies are required just above the floor levels, would make the column very sensitive to small shifts in the 'Load' or 'Resistance' lines. However this would not be a problem in practice, providing the column rein-forcement is only changed gradually at the reinforcement splice locations. A triangular 'code' distribution of load could be used to construct the 'Load Line' but using a first mode load distribution, similar to that indicated in Figure $3(\mathrm{a})$, may result in lower column ductility demand.

STEP 4. Select a floor level, at approximately mid-height of the frame, at which a set of fully ductile column plastic hinges will be permitted to form in the 
frame. The total ideal column plastic hinge strength to be provided at this level is the basic unfactored column moment determined from the equivalent frame in step 3 .

\section{Comments:}

Providing this level of strength for the column plastic hinges should ensure that beam yielding is spread over the height of the frame and that the column plastic hinges are not subjected to high ductility demand due to first mode type loading.

Also, as explained earlier, significant ductility demand is unlikely to occur at this column plastic hinge level under higher modes either.

It is intended that this second set of column plastic hinges will prevent the 'Load Line' from shifting significantly under the influence of higher mode type loading as previously explained in the discussion of Fig 5. It should therefore protect the remainder of the column, over the height of the frame, from significant ductility demand by 'absorbing' the effects of the higher modes.

STEP 5. Obtain the total column strength required for the remainder of the column by multiplying the basic column moments determined in step 3 by a factor to allow for biaxial bending effects and various sources of uncertainty in the analysis.

\section{Comments:}

Factors that may act as a source of uncertainty include the pattern of the beam flexural strengths and the distribution of seismic Dead and Live loads as these may

vary from the distribution that was assumed to apply over the building height.

However, the influence of these factors on column strength requirements will be minimised by the fully ductile midheight column plastic hinges provided in step 4 .

The multiplying factor used in this step could be selected to permit the potential column plastic hinge zones to be detailed for minor to moderate ductility demand as in the current column capacity design proce dure.

STEP 6. At each floor level, distribute the total column strength required amongst the individual columns of the frame. The total column flexural strength required at each floor level will be that determined in step 5 for the equivalent frame.

\section{Comments:}

The method of distribution should aim to minimise the additional ductility demand that will be imposed on individual columns in order to activate the total column strength required. This requires the behaviour of the individual column in the frame to be considered.
When a beam plastic hinging mechanism develops, each column can be modelled in the same way as the equivalent frame shown in Figure. 2 (a) and a 'Resistance Line' like that shown in Figure 2 (c) can be con-structed. However the 'Load Line' for an individual column is indeterminate so that the column bending moments cannot be determined from simple statics.

The column moments could be determined from an inelastic "push-over" analysis of all the bents in the equivalent frame, providing the model analysed had all the bents rigidly linked together at the floor levels. A similar method of analysing frames has recently been advocated by Robinson [3] but, in most cases, a more approximate method of distributing the total column strength would be acceptable if it did not impose excessive additional ductility demand on the columns. The approximate method that will be proposed here is a modification of the current capacity design procedure.

When the current procedure is used, a basic column design moment adjacent to a beam-column joint is obtained from an elastic analysis by amplifying the column moments obtained for code prescribed seismic loads, $M$, by an overstrength factor. The overstrength factor used at each beam-column joint, $\phi$, is found by considering the co'mbined strength of the beams adjacent to the joint. It is the ratio of the beams combined flexural overstrength to the combined design beam moments obtained from the elastic analysis using the code prescribed seismic loads.

This procedure assumes that the elastic distribution of column moments is a good indicator of the inelastic distribution of column moments. However, as discussed above, Figure 2 (c) can also be considered as indicating the inelastic distribution of moments for an individual column. This suggests that the elastic distribution of column seismic moments used in the current design procedure may not be a very good indicator of column strength demand as the inelastic distribution of column moment may be quite different from the elastic distribution. Consequently, it is suggested that the combined flexural overstrength of the beams at a joint, be used directly as the prime indicator of column strength demand in the column adjacent to the joint. Therefore it is proposed that the total column strength required at each floor

level should be determined for the equivalent frame as given in step 5 . The total column strength required should then be distributed to the individual columns of the frame in proportion to the combined flexural overstrength of the beams adjacent to each of the columns at the floor level under consideration.

It is likely that using an average value for the combined flexural 
overstrength of for the beams for each size of column would not impose significant extra ductility demand on the columns. This would mean that, in regular frames with columns of equal size, the reinforcement in all columns within the frame could probably be made the same. This would simplify design, drafting and construction.

STEP 7. At each beam-column joint and using the most adverse column axial load, check that the sum of the ideal column strengths above and below the joint exceeds the combined flexural overstrength of the beams.

\section{Comments:}

Satisfying this condition will ensure that primary plastic hinging takes place in the beams instead of columns. When this condition is not satisfied the column could be strengthened or the distribution of the required total column strength between the individual columns could be modified to ensure that the columns can resist the beam flexural overstrengths.

Alternatively the column could be allowed to plastic hinge and be detailed for full ductility. As permitted by NZS 3101 (Part 1), this should be acceptable when the column is carrying tension or low axial load. The global procedure proposed should still ensure that a soft storey column plastic hinging collapse mechanism does not develop.

When the sum of the flexural overstrengths of the columns is less than that of the beams at a joint, the combined column flexural overstrength would need to be substituted for the combined beam flexural overstrength that was used for the evaluation of $M$

in step 2. The remaining steps would then need to be repeated.

STEP 8. Evaluate the axial and shear forces required for the design of the columns.

\section{Comments:}

No modifications to the current procedure for evaluating column axial loads is proposed. However the current practice of evaluating column design shear forces at each floor level, largely on the basis of local beam overstrengths, does not appear very logical because the shear force at each level is the cumulative total of all loads above that level. It would, there-fore, seem more logical to use a single overstrength factor, $\alpha$, and evaluate the total design shear forces from the load, $\alpha F_{1}$, required to develop a collapse mechanism for an equivalent condensed frame (see Figure $1(\mathrm{a})$ ).

The analysis used to derive the total shear strength required at each floor level would then be the same as that used to derive the total basic column design moments in step 3 .
The current design procedure uses the elastic distribution of column shear forces as the basic design shear forces.

However, once a collapse mechanism develops in a frame the distribution of the total shear force between the columns at each level is highly indeterminate and, like that of the moments, may be quite different from the elastic distribution. Given the fundamental relationship between column moment and column shear force, it would seem logical to distribute the total column shear strength required at each level to the individual columns using the same distribution factors that were used for the column moments in step 6 .

As in the current methodology, the additional effects of concurrency and higher modes on column shear will need to be allowed for. This assumes that the small inelastic shear displacement generated by the higher modes would cause significant deterioration in the column shear strength.

\section{SUMMARY AND CONCLUSIONS}

The behaviour of a building frame responding inelastically to a constantly changing seismic ground motion is a complex phenomenon that is often difficult to interpret. By reducing the frame to an 'equivalent condensed frame' with only one column and examining the behaviour under static loads that model some of the characteristics of dynamic loads, factors influencing column strength requirements are more easily examined.

Two factors are shown to be important. The first is the pattern of seismic lateral load over the height of the building, which is affected by higher modes. The second is the way in which the beam plastic hinge strength varies over the height of the building. The current $\mathrm{NZ}$ capacity design procedure for reinforced concrete columns, given in NZS 3101 (Part 2), takes into account the higher mode effect. However it is suggested that the influence of higher modes may have been over-stated as they are associated with relatively small displacements that would not impose a large ductility demand on the columns. On the other hand, the effect that the beam flexural strength pattern has on column bending moments is not considered in the current design procedure. Under inelastic conditions the column bending moment, at each beam level, is shown to be dependent on the overall pattern of beam flexural strength provided and not on the local beam strength. Consequently, the beam flexural strength pattern provided may result in column plastic hinging under first mode type loading and, as the first mode response is associated with relatively large displacements, high ductility demand could be imposed on the columns. Also, instead of the beam ductility demand being spread throughout the beams of a frame, it may be concentrated in a limited number of 
beams and result in high beam ductility demand.

To avoid this, a number of modifications to the current capacity design procedure for columns are proposed.

The main modification suggested is that the building frame should be evaluated as an equivalent single column frame so that the total column strength required for a beam plastic hinging collapse mechanism to form can be determined.

The other major modification suggested is for fully ductile column plastic hinges to be detailed at about mid-height in the building as well as at the base of the first storey columns. It is anticipated that if these mid-height column plastic hinges are provided with an appropriate strength relative to the remainder of the columns, they will help protect the remainder of the columns from significant ductility demand.

Some illogical aspects of the current method of evaluating the required shear strength of columns are examined and a revised procedure is proposed.

These conclusions and suggestions can only be regarded as tentative until they are more fully evaluated using inelastic dynamic analysis. It is hoped that a source of funding can be found to enable this work to be carried out in the near future.

\section{ACKNOWLEDGEMENTS}

The author is indebted to the Works and Development Services Corporation (NZ) Ltd for drafting and typing support during the preparation of this paper. Helpful suggestions of wORKS structural office staff are also gratefully acknowledged.

\section{REFERENCES}

1. SANZ, 1982, "NZS 3101, Part 1: Code of Practice for the Design of Concrete structures and part 2: Commentary on the Design of Concrete Structures". Standards Association of New Zealand, Wellington, New Zealand.

2. Paulay, T, 1979, "Developments in the Design of Ductile Reinforced Concrete Frames", Bulletin of NZNSEE, Vol. 12.

3. Robinson, L.M. , 1989, "Towards a General Capacity Design Procedure for Buildings". Vol. 1, Proceedings IPENZ Annual Conference, Dunedin, New Zealand.

4. Clough, R.W. , Penzien, J., 1975, "Dynamics of Structures", McGraw - Hill, Tokyo.

5. Fenwick, R.C., Davidson, B.J., 1989, "Dynamic Behaviour of Multi-storey Buildings", Report No. 463, University of Auckland, School of Engineering. (Note: Participation factors and mode shapes were obtained from the authors in private correspondence). 